\title{
LINE PROFILES AND MAGNETIC FIELDS IN THE LIMB SOLAR FLARE OF JULY 17, 1981. PRELIMINARY RESULTS
}

\author{
V. G. Lozitsky (D), I. I. Yakovkin (D), N. I. Lozitska (D) \\ Astronomical Observatory of the Taras Shevchenko National University of Kyiv, \\ e-mail: lozitsky_v@ukr.net,yakovkinii@gmail.com, olozitsky@gmail.com \\ (Received 23 January 2020; in final form 17 March 2020; accepted 09 April 2020; published online 27 April 2020)
}

\begin{abstract}
The limb solar flare of 17 July 1981 is studied according to the observations carried out with the Echelle spectrograph of a horizontal solar telescope of the Astronomical Observatory of Taras Shevchenko National University of Kiev. For $8^{h} 17^{m}$ UT, close to the flash phase, the $I \pm V$ profiles of the K Ca II $3933.7 \AA$ and He I 4471.5 $\AA$ lines are analyzed. At the indicated moment, these lines had two components of emission, narrow and wide, which were mutually shifted on 1.8-2 . The narrow component had a full half-width of $0.24 \AA$ in the K Ca II line and $0.34 \AA$ in the He I line. The wide component had the full half-widths of $3.3 \AA$ and $4.1 \AA$, respectively, for these lines. The magnetic field magnitude in the flare, measured by splitting the narrow component, varies in the picture plane and reaches $1300 \pm 200 \mathrm{G}$ for the K Ca II line and $2100 \pm 200 \mathrm{G}$ for the He I line. Such features are found at the altitudes of about 10-14 Mm above the level of the photosphere. It is important to note that the true values of the local magnetic fields in the flare could be even larger, since the obtained results represent a longitudinal component of the magnetic field, with the assumption that the filling factor equals unity. On the basis of the comparison of the Doppler widths of the narrow component in the two lines under study, the following estimations of kinetic temperature and turbulent velocity were obtained: $T=17000 \pm 1000 \mathrm{~K}$, and $\xi_{\text {turb }}=10.8 \pm 0.3 \mathrm{~km} / \mathrm{sec}$.
\end{abstract}

Key words: Sun, solar activity, limb solar flare, profiles of K Ca II and He I lines, solar magnetic fields, "kilogauss" strengths, turbulent velocity.

DOI: https://doi.org/10.30970/jps.24.2901

\section{INTRODUCTION}

Limb solar flares are of particular interest for several reasons. Firstly, such observations make it possible to more directly determine the height of the relevant structural elements of the flare in the atmosphere, without reference to a semi-empirical model of the flare. Secondly, limb flares give a simpler spectrum that does not overlap with the Sun's photosphere spectrum. The interpretation of that spectrum does not require a separation of the contributions of the flare itself and the photosphere under the flare. In principle, such a separation is possible, but only based on the construction of a semi-empirical model of the flare, and the latter is always based on certain model assumptions. Thirdly, in limb flares the magnitude of the horizontal component of the magnetic field vector can be estimated more directly. In flares on the solar disk, the value close to the radial component, that is, vertical to the surface of the Sun, is estimated. The latter is due to the fact that in solar flares, unlike sunspots, there is generally an incomplete spectral separation of Zeeman's sigma components of spectral lines, even in relatively narrow emissions of Fe I lines [1]. In this case, the longitudinal component of the field vector is determined directly from the observations. For flares on the Sun's disc, the longitudinal component is essentially close to the radial one. To date, there are very few data in the literature about magnetic fields in limb flares. The first measurements of this kind were made by Koval [2] in the $\mathrm{H} \alpha \lambda=6562.8 \AA$ line. It was found that the magnitude of the magnetic field, measured by the relative splitting of the line in orthogonal circular polarizations (i.e., in the $I+V$ and $I-V$ spectra, where
$I$ and $V$ are the corresponding Stokes parameters), is typically several hundred gauss $(\mathrm{G})$. However, a case of a rather significant relative displacement of the $I \pm V$ profiles corresponding to a magnetic field of $9000 \mathrm{G}$ was also detected. The author [2] had the following point of view: "However, such large values are unlikely in the light of existing ideas about the structure of magnetic fields in the solar atmosphere." It should be noted that even magnetic fields of $10^{2} \mathrm{G}$ are 'too strong' for limb flares. Indeed, if the magnetic field tube is homogeneous and non-twisted, then the upper limit of $B_{\max }$ in the tube can be estimated from the simple condition of the equality of the magnetic pressure $B^{2} / 8 \pi$ inside the tube and the gas pressure $P=n k T$ outside the tube. Limb solar flares occur in the chromosphere and lower corona, where the gas pressure in undisturbed atmosphere is $\sim 10^{-1} \div 10^{2}$ dyn $/ \mathrm{cm}^{2}$. However, at that pressure, $B_{\max }$ should be $\sim 1 \div 50 \mathrm{G}$, which is at least an order of magnitude less than observed. Furthermore, given that the observations with a circular polarization analyzer give a mainly longitudinal component of the magnetic field, then the magnitude of the magnetic field may be even larger. One can expect that such strong magnetic fields can occur in strongly twisted magnetic structures like force-free ropes [3].

Similar strong magnetic fields were measured in the limb solar flare of $X 1.2$ class on July 14, 2005 too [4]. The obtained results relate mainly to the lower solar corona and correspond to the altitudes of 2-10 megameters $(\mathrm{Mm})$ above the level of the photosphere. From the measurements by the "center of gravity" method for $I \pm V$ profiles of the $\mathrm{H} \alpha$ line, it was concluded that the magnetic fields of the intensity $B=200-300 \mathrm{G}$ existed at the indicated heights. However, a detailed study of the 
bisectors of $I \pm V$ profiles showed that the magnetic field in the flare volume was significantly heterogeneous, which is evident from the fact that the bisectors of the $I \pm V$ profiles were non-parallel. In particular, a local peak of the bisector splitting was detected at a considerable distance $\Delta \lambda$ from the line core $(\Delta \lambda \approx 1.1 \AA)$, which can indicate the presence of very strong magnetic fields of $\sim 10^{4} \mathrm{G}$ range.

The magnetic fields of the order of $10^{2} \mathrm{G}$ were measured using the $\mathrm{H} \alpha$ line also in the limb solar flare of M7.7 class on July 19, 2012 [3]. The results obtained refer to a rather high altitude above the limb, about $40 \mathrm{Mm}$. In this case, a significant lack of parallelism of the bisectors of $I \pm V$ profiles was observed too, with a maximum of their splitting at the distance of $0.4 \AA$ from the center of the emission profile. In the mentioned paper, a theoretical MHD force-free model was proposed that allows explaining the existence of such strong fields in the corona by the strong twisting of the power lines. According to numerical estimations within the frame of the model, the magnetic field strength increases by about 2 orders in comparison with the weak external field of 1-2 G level, which is typical of the solar corona.

In this paper, we present preliminary results of the magnetic field study in a limb solar flare on July 17, 1981, which is interesting because its spectra contained a very narrow emission component in the $\mathrm{Ca}$ II and He I lines. It seems attractive to estimate the magnetic field in the flare precisely from these lines, and not from the $\mathrm{H} \alpha$ line, as in the above studies. In the future, we plan to study here the hydrogen emissions too. According to the data obtained, the narrow component is less pronounced in hydrogen emissions; additional discussion points are possible there, which we would like to leave outside the scope of this article.

\section{OBSERVATIONS}

The solar flare on July 17, 1981 occurred on the eastern limb of the Sun, in the vicinity of the place with coordinates $7^{\circ} \mathrm{S}, 90^{\circ} \mathrm{E}$. According to the bulletin Solnechnye Dannye [5], the flare was associated with the active region №325, which appeared on the Sun's disk the next day, July 18, 1981. This flare was observed with the Echelle spectrograph of the horizontal solar telescope at the Astronomical Observatory of the Taras Shevchenko National University of Kyiv (HST AO KNU) [6], starti$\mathrm{ng}$ from about $8^{h} 15^{m} \mathrm{UT}$, with the first shot of the flare spectrum taken at $8^{h} 17^{m}$ UT. This time corresponds, apparently, to the flash phase of the flare, which is evident from the very wide wings of the lines (Fig. 1).

The flare was observed by N. I. Lozitska, V. G. Lozitsky and P. M. Polupan. The flare emission was initially observed in a spectrohelioscope, which allows observing the entire "royal" (near-equatorial) zone of the Sun's disk in the light of the $\mathrm{H} \alpha$ line. While identifying the flare position in white light at the entrance slit of the Echelle spectrograph, Natalia Lozitska noticed an interesting detail: this flare was visible for some time also in whi- te light as a small arched feature on the Sun's limb. As we know from literature, limb solar flares were no longer observed in white light. It should be noted that to make such observational manifestations possible, the optical thickness must be close to unity, which needs the plasma density in the flare to be in the range of photospheric value $\left(\sim 10^{16} \mathrm{~cm}^{-3}\right)$, which was indeed observed, at least at the level of the chromosphere [7]. According to our estimation, the optical flare class was $2 \mathrm{~B}$, which is higher than suggested by the bulletin Solnechnye Dannye [5] (SB). However, we did not perform the exact measurements of the flare area required to strictly determine its class. The main value of our observations is the observed $I \pm V$ spectra with interesting emissions, which make it possible to determine the magnetic field strength and other physical parameters by the profiles of the lines of different chemical elements.

The flare spectrum was photographed on WP1 ORWO photo-plates with the exposures of $10 \div 30 \mathrm{sec}$. In the $8^{h} 17^{m} \div 9^{h} 51^{m}$ UT time interval, six exposures were made. The entrance slit was perpendicular to the solar limb. Below, the first Zeeman spectrogram obtained in $8^{h} 17^{m} \mathrm{UT}$ with exposure of $10 \mathrm{sec}$ is analyzed.

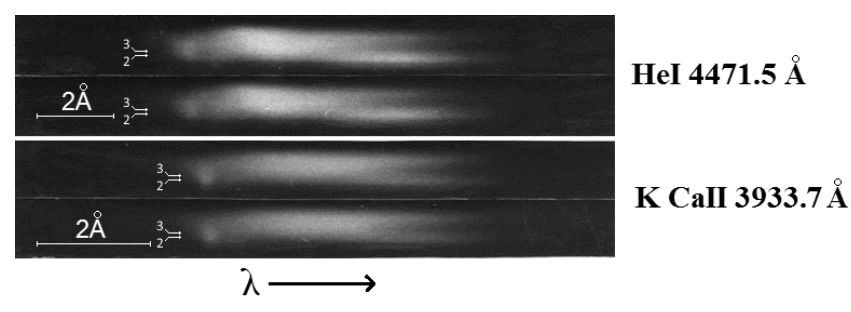

Fig. 1. Positives of He I 4471.5 and K Ca II 3933.7 lines on the spectrogram for the $8^{h} 17^{m}$ UT. Each line is represented by two images that correspond to the $I+V$ and $I-V$ spectra. The width of each stripe corresponds to approximately 32 arc sec or $23 \mathrm{Mm}$ on the Sun.

The value of the obtained spectra is not only in the fact that they capture the extreme manifestation of solar activity from a very interesting perspective (see above), but also in the fact that the $I+V$ and $I-V$ spectra are obtained simultaneously, on separate adjacent bands of the spectrum (Fig. 1). This is due to the fact that the circular polarization analyzer used a $\lambda / 4$ plate in front of the entrance slit of the spectrograph and a prism splitter of Icelandic spar (analogous to the Wollaston prism) behind the entrance slit. Therefore, the $I+V$ and $I-V$ spectra relate to the same moment of time and the same places in the Sun.

\section{PROFILES OF SPECTRAL LINES}

A visual inspection of the spectrogram for $8^{h} 17^{m}$ has shown that it contains well visible emissions of hydrogen, helium and $\mathrm{Ca}$ II. In this preliminary study, we present results obtained by K Ca II $3933.7 \AA$ and He I $4471.5 \AA$ lines only. It is necessary to note that these lines have very different excitation potentials of the lower term, namely, $0.00 \mathrm{eV}$ for the first line and $20.87 \mathrm{eV}$ for the 
second [8]. Also, the masses of the corresponding atoms are very different, too: about $40 \mathrm{~m}_{u}$ for calcium and only $4 \mathrm{~m}_{u}$ for helium. Therefore, assuming that there were volumes (components) with different temperatures in the flare, we can expect that the emission in the $\mathrm{K} \mathrm{Ca}$ II line was formed mainly in the low-temperature component, whereas the emission of the He I line was in the highertemperature component. Obviously, this should manifest itself in some way on the observed spectra.

In reality, the shapes of the K Ca II $3933.7 \AA$ and He I $4471.5 \AA$ lines clearly indicate that there were at least two emission components in these lines: a wide and a narrow one, 1.8-2 $\AA$ apart in wavelength (Fig. 1). Regarding the narrow component, its features are best seen on the photometrical profiles of the lines obtained after the photometry of the spectrogram on the M-4 micro-photometer (Figs. 2 and 3).

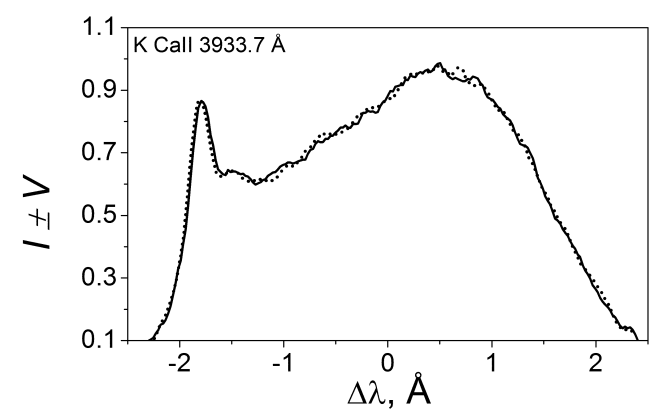

Fig. 2. The $I \pm V$ profiles of the $\mathrm{K} \mathrm{Ca}$ II line in the studied flare in the photometric section No. 2. The presence of a narrow component in the "blue" wing of the emission of the flare (at $\Delta \lambda \approx-1800 \mathrm{~m} \AA$ ) is clearly visible.

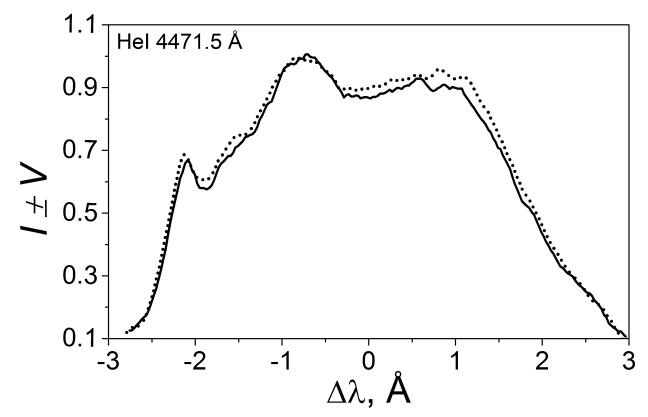

Fig. 3. The $I \pm V$ profiles of the He I line in the investigated flare in the photometric section No. 3. The narrow component (at $\Delta \lambda \approx-2 \AA$ ) is less pronounced here than in the $\mathrm{K} \mathrm{Ca} \mathrm{II}$ line.

Probably, the origin of the narrow spectral component is associated with enhanced magnetic fields of regular polarity, which reduce the stochastic component of the velocity and increase the ordered component corresponding to the circular motions of the plasma around the lines of force. For the observations of longitudinal magnetic fields (i.e., along the lines of force), this should lead to the appearance of narrow spectral lines. From this point of view, a broad component can occur in areas of flare with a much weaker magnetic field or in volumes with mixed-polarity fields. In both cases, the Zeeman splitting of the broad component should be observed close to zero. It means that this component can be used as a suitable spectral reference, i.e. a spectral peculiarity with the same wavelength in spectra $I+V$ and $I-V$.

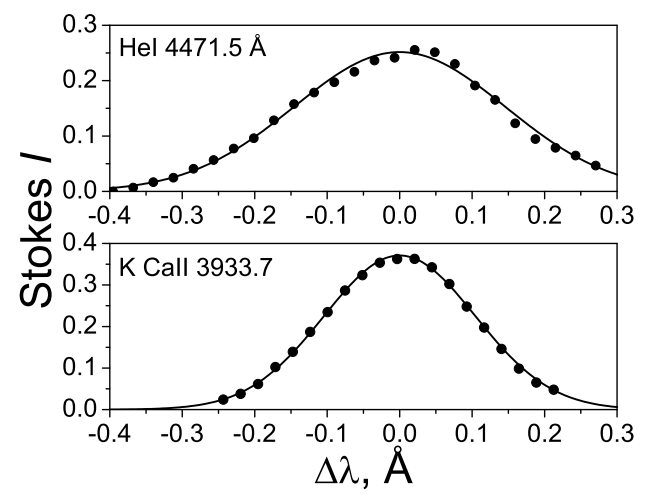

Fig. 4. The extracted ("pure") Stokes $I$ profiles of narrow spectral component for lines under study. Black circles present observations and solid curves show closest Gaussian profiles.

It can be seen that this narrow component is more pronounced in the $\mathrm{K}$ Ca II line. The profiles presented in Figs. 2 and 3 correspond to the photometric sections, which in Fig. 1 are pointed by small arrows with numbers 2 and 3 to the left of the narrow emission. The height of the slit of the micro-photometer was equivalent to $2.5 \mathrm{Mm}$ in the Sun. Given that the wide emission component in this line is quite close in shape to the Gaussian distribution, it was possible to separate the two emission components, considering that the narrow component can also be approximated by Gaussian (Fig. 4). Then the true full spectral half-width of the narrow emission component (that is, the "blue" peak at $\Delta \lambda \approx-1800 \mathrm{~m} \AA$ in Fig. 2) is as follows: $\Delta \lambda_{1 / 2}=(240 \pm 8) \mathrm{m} \AA$, which corresponds to its Doppler width $\Delta \lambda_{\mathrm{D}}=(146 \pm 5) \mathrm{m} \AA$.

The similar procedure for the He I line is somewhat less straightforward, since the broad component there is clearly not Gaussian. However, since for this line the "blue" peak (at $\Delta \lambda \approx-2 \mathrm{~A}$ ) is quite narrow spectrally too, this can be done with satisfactory accuracy at the level of photometry errors (1-2\%). That leads to $\Delta \lambda_{1 / 2}=$ $(340 \pm 12) \mathrm{m} \AA$ and $\Delta \lambda_{\mathrm{D}}=(204 \pm 7) \mathrm{m} \AA$.

Assuming that these narrow "blue" peaks in the $\mathrm{He}$ I 4471.5 and K Ca II 3933.7 line profiles were formed in the same space volumes, we can estimate the kinetic temperature $T$ and the turbulent velocity $\xi_{\text {turb }}$ in them, based on the known formula

$$
\Delta \lambda_{\mathrm{D}}=\left(\lambda_{0} / c\right) \times\left(2 k T / m+\xi_{\text {turb }}^{2}\right)^{1 / 2}
$$

where $\lambda_{0}$ is the unperturbed wavelength of the spectral line, $c$ is the speed of light, $k$ is the Boltzmann constant, $m$ is the mass of the atom. This estimation leads to $T=17000 \pm 1000 \mathrm{~K}$ and $\xi_{\text {turb }}=10.8 \pm 0.3 \mathrm{~km} / \mathrm{sec}$. 
The thermal velocities $v$ are as follows: $v_{\mathrm{HeI}}=8.4 \pm$ $0.3 \mathrm{~km} / \mathrm{sec}, v_{\text {CaII }}=2.7 \pm 0.1 \mathrm{~km} / \mathrm{sec}$.

For comparison, Polupan [9] obtained $\xi_{\text {turb }}=$ $19 \mathrm{~km} / \mathrm{sec}$ for the large solar flare on July 12, 1961, analyzing only the Balmer lines from $\mathrm{H} \alpha$ to $\mathrm{H}_{13}$ (notice, these lines were not photographed simultaneously). The same author [10] found that the electron temperature $T_{\mathrm{e}}$ was $10000 \mathrm{~K}$ in the limb flare on October 11, 1957. This comparison shows the closeness of our estimates with the data $[9,10]$. A perfect coincidence may not be an ideal case here for three reasons: (a) solar flares are very different in their physical characteristics and evolutionary changes, (b) different methods of determining their physical parameters give, in general, different results (c) physical parameters can changes essentially along the line of sight in the flare [7]. It is useful to remember that the electron temperature $T_{\mathrm{e}}$ coincides with the kinetic $T$ only under the condition of local thermodynamic equilibrium (LTE), and this is performed only in the deep layers of the photosphere, but not in the chromosphere and corona [11]. The similar estimates for the wide emission component in He I 4471.5 and K Ca II lines are less reliable than for the narrow one.

Comparing the profiles in Figs. 2 and 3, it can be seen that the wide component in the He I line is possibly the result of the summation of two smaller width profiles spaced by wavelength of $1.8 \AA$. There are no similar indications for the presence of two narrow and spaced profiles in the K Ca II line (Fig. 2). In this regard, the assumption that these two lines are emitted in the same volume is clearly not applicable here. This is quite expected, given the very large difference in the excitation potentials of the lower term of these lines (20.87 and $0.00 \mathrm{eV}$, respectively).

\section{MAGNETIC FIELDS}

To determine the magnitude of the magnetic field, it is necessary to measure the relative displacement of the $I+V$ and $I-V$ profiles. However, the problem in this case is that there are no telluric or magnetically non-sensitive (with $g_{\text {eff }}=0$ ) lines near the studied lines that could be used for the spectral "tie", assuming that their position in both spectra corresponds to the same wavelength. Therefore, an approximate method was used, whose essence is as follows.

First, the $I+V$ and $I-V$ profiles were tied to each other on condition that their "centers of gravity" coincide in both polarizations. Obviously, the main contribution to the definition of these "centers of gravity" was made by the wide emission component, since it is an order of magnitude wider than the narrow component, and the corresponding intensities of the two components are generally commensurate. This linking revealed that in some places on the Sun an obvious splitting of a narrow component had existed, which is manifested in the relative displacement of its peaks in the spectra of opposite polarizations (Fig. 5).

In the case shown in Fig. 5, the splitting of the narrow peaks is approximately $22 \mathrm{~mA}$, which means that the Zeeman splitting $\Delta \lambda_{\mathrm{H}}$ is $11 \mathrm{~m} \AA$. According to multiplet tables [8], the K Ca II 3933.7 $\AA$ corresponds to transition $4^{2} S-4^{2} P^{0}, J=1 / 2-3 / 2$. For the case of spin-orbital interaction ( $L S$ coupling), the effective Landé factor $g_{\text {eff }}$ should be 1.167, which gives the following formula to determine the magnitude of the magnetic field $B$ :

$$
B=1.186 \times 10^{5} \Delta \lambda_{\mathrm{H}}
$$

where $B$ is expressed in Gauss $(\mathrm{G})$ and $\Delta \lambda_{\mathrm{H}}$ in angstroms ( $\AA$ ). Then for $\Delta \lambda_{\mathrm{H}}=11 \mathrm{~m} \AA$ we have $B=1300 \mathrm{G}$ with a measurement error of about $\pm 200 \mathrm{G}$. This is a fairly strong magnetic field, given that the corresponding flare point corresponds to approximately $12 \mathrm{Mm}$ above the level of photosphere. Similar measurements at other flare points gave the following results: $B=1200 \pm 200 \mathrm{G}$ for photometric section No. 1 and $B=400 \pm 200 \mathrm{G}$ for photometric section No. 3 .

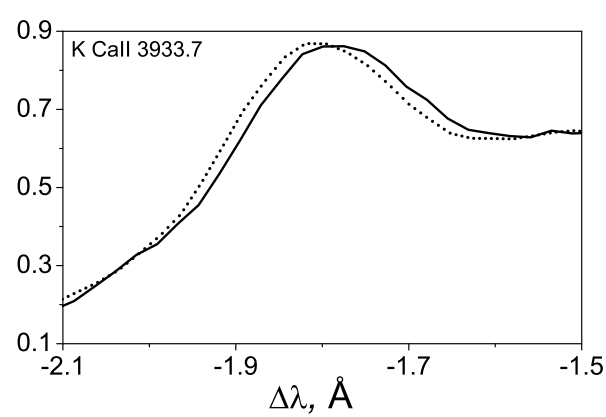

Fig. 5. Splitting of a narrow component of the K Ca II line in the photometric section No. 2.

A similar splitting of narrow emission peaks was observed in He I 4471.5 line too (see Fig. $3, \Delta \lambda_{\mathrm{H}} \approx-2$ $\AA)$. In particular, the splitting of these peaks is about $40 \mathrm{~m} \AA$ in the photometric section No. 3, which means $\Delta \lambda_{\mathrm{H}} \approx 20 \mathrm{~m} \AA$. According to [12], this line corresponds to transition ${ }^{3} P_{4}-{ }^{3} D_{7}$, which gives $g_{\text {eff }}=1.12$ for the case of $L S$ coupling. In this case, the connection between the magnetic field strength $B$ and Zeeman splitting $\Delta \lambda_{\mathrm{H}}$ is as follows:

$$
B=1.07 \times 10^{5} \Delta \lambda_{\mathrm{H}}
$$

From (3) it follows that if $\Delta \lambda_{\mathrm{H}} \approx 20 \mathrm{~m} \AA$ then $B \approx 2100$ $\mathrm{G}$. Thus, the measurements in both lines indicate very strong magnetic fields in the flare, of the "kilo-Gauss" level.

\section{CONCLUSIONS AND DISCUSSION}

Based on the study of the $I \pm V$ profiles of the limb solar flare on July 17, 1981, one can conclude that the K Ca II 3933.7 and He I 4471.5 lines had at least two-component emissive profiles, namely, a narrow and 
a wide one. In the Gaussian approximation, the narrow component had a full width of $0.24 \AA$ in the first line and $0.34 \AA$ in the second. The wide components were broader by more than an order of magnitude, with the widths of $3.3 \AA$ and $4.1 \AA$, respectively. The magnitude of the magnetic field, found by measuring the splitting of the narrow component, varies in the picture plane of the flare and reaches $1200-1300 \mathrm{G}$ for the K Ca II line. The same order of the magnetic field magnitude was found from the measurements by He I line. Such features were found at the altitudes of about $10-14 \mathrm{Mm}$ above the level of the photosphere. The kinetic temperature $T$ and turbulent velocity $\xi_{\text {turb }}$ were here as follows: $T=17000 \pm 1000 \mathrm{~K}$ and $\xi_{\text {turb }}=10.8 \pm 0.3 \mathrm{~km} / \mathrm{sec}$.

Apparently, we first observed the case when a very narrow and a very wide flare emission were significantly shifted in wavelengths, by 1.8-2 A. Previously, there were cases when these emissions practically coincided in wavelengths $[1,7]$. Very narrow emissions, 3-4 times narrower than the observed line profiles, were assumed in [13] in order to explain the shape of the bisectors of the $I \pm V$ profiles in the prominences. In particular, it has been shown that by assuming the two-component emission of the prominences and the true width of a narrow subtelescopic component within $0.1-0.25 \AA$, it is possible to explain the different shapes of the bisectors of these profiles, namely, like the Latin letter "V" and also the "loop" type. These values of the width of the narrow emission in the prominences are generally lower than the stated above for the investigated flare, but it should be noted that in [13] much less intense manifestations of solar activity were studied.

Regarding the magnetic field strengths, similar (and even larger) values were measured in active prominences by $\mathrm{H} \alpha$ and D3 He I lines [14]. The altitude range where such field values were found is also close in both cases. In [14], attention was drawn to an interesting effect that has no analogues in the works of other researchers, namely to the anti-correlation of magnetic field values along the lines $\mathrm{H} \alpha$ and D3 He I, up to their opposite polarity (see Fig. 5 in the mentioned paper). Thus, it confirms the earlier conclusion by Yakovkin and Zeldina [15] that the hydrogen and helium emissions are formed in prominences, in general, in different spatial volumes. It should also be noted that the true values of the local magnetic fields in the flare could be even larger for two reasons: (1) the obtained results represent a longitudinal component of the magnetic field, and (2) it was assumed that filling factor $f$ is close to unity $(f \approx 1)$.

In principle, the high magnetic field strengths in the limb solar flare under study do not contradict in their order of magnitude some estimates of other authors obtained for approximately the same heights in the corona above the active regions. So, Brosius and White [16] measured the magnetic field of $1750 \mathrm{G}$ at the height of $8000 \mathrm{~km}$ above a large sunspot in NOAA AR 10652 at the west solar limb on 2004 July 29 using coordinated observations with the Very Large Array, the Transition Region and Coronal Explorer, and three instruments (CDS, EIT, MDI) aboard the Solar and Heliospheric Observatory. Reznikova et al. [17] estimated the field value to be approximately 1 kilogauss in the limb flare loop for the 2002 August 24 event. These estimates follow from the analysis of radio emission under certain model assumptions. That is, they are not direct measurements, like our measurements by the Zeeman effect. In addition, the flare investigated in the present article is a much more powerful event, compared to the events in [16] and [17]. In this case, we can expect especially strong magnetic fields. As for the measurements of spatially unresolved magnetic fields in this flare, which correspond to filling factor $f \ll 1$, they require some special methods, for example, the analysis of bisectors of $I \pm V$ profiles [18, 19]. This is planned to be done in the future.

Acknowledgements. The authors are heartily grateful to unknown referees for numerous useful notes and valuable advice. This study was funded by the Taras Shevchenko National University of Kyiv, projects Nos. 19БФ023-01 and 19БФ023-03.
[1] V. G. Lozitsky, Bull. Taras Shevchenko Natl. Univ. Kyiv, Astronomy 57, 47 (2018).

[2] A. N. Koval, Bull. Crim. Astrophys. Obs. 57, 106 (1977).

[3] E. A. Kirichek, A. A. Solov'ev, N. I. Lozitskaya, V. G. Lozitskii, Geomagn. Aeronomy 53, 831 (2013); https://do i.org/10.1134/S0016793213070116.

[4] V. G. Lozitsky, M. M. Statsenko, in Proceeding of $3^{\text {rd }}$ Int. Sci. Seminar "Physics of the Sun and stars" (Kalmyk University, Elista, 2006), p. 46.

[5] Soln. Dannye No 7, 19 (1981).

[6] V. G. Lozitsky, Adv. Space Res. 57, 398 (2016); https: //doi.org/10.1016/j.asr.2015.08.032.

[7] V. G. Lozitsky, E. A. Baranovsky, N. I. Lozitska, V. P. Tarashchuk, Mon. Not. Roy. Astron. Soc. 477, 2796 (2018); https://doi.org/10.1093/mnras/sty738.

[8] C. E. Moore, Contr. Princeton Univ. Observ., No. 20
(Princeton, New Jersey, 1945).

[9] P. N. Polupan, Soln. Dannye No. 4, 106 (1972).

[10] P. N. Polupan, Astron. Zh. 37, 1032 (1960).

[11] M. I. Stodilka, Kinem. Fiz. Nebes. Tel 16, 291 (2000).

[12] P. L. Smith, C. Heise, J. R. Esmond, R. L. Kurucz, Atomic spectral line database from CD-ROM 23 of R. L. Kurucz (Smithsonian Astrophysical Observatory, Cambridge, Mass, 1995); https://www.cfa.harvard.ed u/amp/ampdata/kurucz23/sekur.html.

[13] V. Lozitsky, V. Masliukh, O. Botygina, Bull. Taras Shevchenko Nat. Univ. Kyiv, Astronomy 52, 7 (2015).

[14] V. G. Lozitsky, O. A. Botygina, Astron. Lett. 38, 380 (2012); https://doi.org/10.1134/S1063773712050 039.

[15] N. A. Yakovkin, M. Yu Zeldina, Solar Phys. 45, 319 (1975); https://doi.org/10.1007/BF00158453. 
[16] J. W. Brosius, S. M. White, Astrophys. J. 641, L69 (2006); https://doi.org/10.1086/503774.

[17] V. E. Reznikova et al., Astrophys. J. 697, 735 (2009); https : //doi .org/10.1088/0004-637X/697/1/735.

[18] M. Gordovskyy, V. G. Lozitsky, Solar Phys. 289,
3681 (2014); https://doi.org/10.1007/s11207-014-0 546- 2 .

[19] V. G. Lozitsky, Adv. Space Res. 55, 958 (2015); https: //doi.org/10.1016/j.asr.2014.09.028.

\title{
ПРОФІЛІ ЛІНІЙ І МАГНІТНІ ПОЛЯ В ЛІМБОВОМУ СОНЯЧНОМУ СПАЛАХУ 17 ЛИПНЯ 1981 р. ПОПЕРЕДНІ РЕЗУЛЬТАТИ
}

\author{
В. Г. Лозицький, І. І. Яковкін, Н. Й. Лозицька \\ Астрономічна обсерваторія Киӥвсъкого націоналъного університету імені Тараса Шевченка, \\ вул. Обсерваторна, 3, Київ, 04053, Украӥна \\ e-mail: lozitsky_v@ukr.net,yakovkinii@gmail.com,olozitsky@gmail.com
}

\begin{abstract}
Вивчено лімбовий сонячний спалах 17 липня 1981 р. за даними спостережень, отриманими на ешельному спектрографі горизонтального сонячного телескопа Астрономічної обсерваторії Київського національного університету імені Тараса Шевченка. Для моменту $8^{h} 17^{m} \mathrm{UT}$, близького до флаш-фази спалаху, проаналізовано профілі $I \pm V$ ліній K Ca II $3933.7 \AA$ та Не I $4471.5 \AA$. У вказаний момент ці лінії мають двокомпонентну емісію, вузьку й широку, які взаємно зміщені на 1.8-2 А. Вузька компонента має півширину $0.24 \AA$ в лінії K Ca II і $0.34 \AA$ в лінії Не I. Широка компонента має півширину $3.3 \AA$ і $4.1 \AA$, відповідно, в цих лініях. Магнітне поле у спалаху, виміряне за розщепленням вузької компоненти, змінюється в картинній площині й досягає $1300 \pm 200$ Гс по лінії K Са II і $2100 \pm 200$ Гс по лінії Не І. Такі особливості були виявлені на висотах приблизно 10-14 Мм над рівнем фотосфери. Важливо підкреслити, що дійсні величини локальних магнітних полів у спалаху могли бути ще більшими, позаяк отримані результати представляють поздовжню компоненту магнітного поля, притому у припущенні, що фактор заповнення близький до одиниці. Профілі вузької компоненти є гауссовими, що вказує на малу оптичну товщу емісії й на відсутність значних макроскопічних рухів. Це дозволило отримати прості оцінки кінетичної температури $T$ і турбулентної швидкості

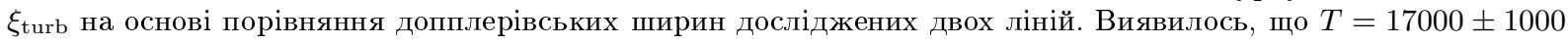
$\mathrm{K} \mathrm{i} \xi_{\text {turb }}=10.8 \pm 0.3 \mathrm{kм} /$ сек, що добре узгоджується з даними інших авторів для сонячних спалахів.
\end{abstract}

Ключові слова: Сонще, сонячна активність, лімбовий сонячний спалах, профілі ліній К Сa II i He I, сонячні магнітні поля, “кілогауссові" напруженості, турбулентні швидкості. 